$\begin{array}{llllll}\text { C } & & \text { A } & & & \\ \text { R } & \text { E } & \text { P } & \text { O } & \text { R } & \text { T }\end{array}$

Janet SW Wu 胡詩穎
WT Poon 潘永達
CK Ma 馬子軍
ML Chen 陳武龍
KS Pang 彭權森
Tony WL Mak 麥永禮
HB Chan 陳衍標

\title{
Budd-Chiari syndrome secondary to toxic pyrrolizidine alkaloid exposure
}

In this report, we describe a case of pyrrolizidine alkaloid-related Budd-Chiari syndrome in Hong Kong. A 10-month-old boy presented with ascites, right pleural effusion, and hepatomegaly after consumption of herbal drinks for 3 months. His clinical (including imaging) features were compatible with Budd-Chiari syndrome. Budd-Chiari syndrome is a rare disease entity in paediatric patients. In our case, extensive workup performed to look for the underlying cause of Budd-Chiari syndrome was unrevealing, except for toxic pyrrolizidine alkaloid exposure in his herbal drinks.

\section{Case report}

A 10-month-old boy was admitted to the Department of Paediatrics and Adolescent Medicine of United Christian Hospital of Hong Kong in August 2009, with complaints of abdominal distension and scrotal swelling for 1 week. He was born in Hong Kong, but soon after birth he went to Kaiping, Guangdong with his parents. He enjoyed good past health and received vaccines according to the local immunisation programme. Physical examination revealed hepatomegaly with liver palpable $12 \mathrm{~cm}$ below the right costal margin. The abdomen was distended and revealed shifting dullness, and there was scrotal oedema. Chest examination yielded decreased breath sounds over the right chest. Initial laboratory tests showed elevated alanine transaminase (ALT) of 287 (reference range, 8-36) IU/L and a prothrombin time of 19 (reference range, 10-12) seconds, and an activated partial thrombin time of 30 (reference range, 29-37) seconds. Complete blood count, bilirubin, albumin, renal function, inflammatory markers (including C-reactive protein and erythrocyte sedimentation rate), and serological markers for viral hepatitis yielded nil abnormal. The chest X-ray showed a right pleural effusion. Abdominal ultrasound, including Doppler study, revealed ascites and hepatomegaly. The right hepatic vein appeared thrombosed with an absent colour signal, and the middle and left hepatic vein showed distorted pulse Doppler signals with loss of the triphasic pattern. The intrahepatic portion of the inferior vena cava (IVC) was markedly narrowed. The main portal vein was patent with a normal flow direction. Computed tomography (CT) of the abdomen also showed a small IVC (Fig 1) and patent portal veins but hepatic veins were not well demonstrated. These clinical features and imaging findings were compatible with BuddChiari syndrome (BCS).

The complete blood count and peripheral blood smear were normal. Bone marrow

Key words

Ascites; Budd-Chiari syndrome; Pleural effusion; Pyrrolizidine alkaloids

Hong Kong Med J 2013;19:553-5 DOI : 10.12809/hkmj133779

Department of Paediatrics and Adolescent Medicine, United Christian Hospital, Kwun Tong, Hong Kong JSW Wu, MB, BS

CK Ma, MRCP (Glasg), FHKAM (Paediatrics)

HB Chan, MB, BS, FHKAM (Paediatrics) Hospital Authority Toxicology Reference Laboratory, Department of Pathology, Princess Margaret Hospital, Laichikok, WT Poon, MB, ChB, FHKAM (Pathology) ML Chen, $\mathrm{MSc}, \mathrm{ACB}(\mathrm{HK})$

TWL Mak, MB, ChB, FHKAM (Pathology) Hong Kong Herbarium, Agriculture, Fisheries and Conservation Department, Hong Kong KS Pang, BSc, MS

Correspondence to: Dr TWL Mak Email: makwl@ha.org.hk aspirate and trephine showed no abnormal infiltrate. The thrombophilia test showed a mildly decreased protein $C$ level of 0.6 (reference range, $0.7-1.3$ ) IU/mL and a total protein $\mathrm{S}$ level of 0.64 (reference range, $0.67-1.13$ ) IU/mL. No serum lupus anticoagulant or anticardiolipin antibodies were detected. Anti-thrombin III and activated protein $\mathrm{C}$ resistance were normal. Screening for infections, autoimmune markers, metabolic derangements, and alpha-1-antitrypsin deficiency was non-contributory.

Further enquiry revealed that the mother had given the patient herbal drinks for 3 months to 'improve health'. The drinks were prepared from plants grown in her garden that were boiled in water. She could not recall the exact frequency of administration or the amounts used. A pack of unused plants was later brought by parents from the Mainland and identified by a botanist to contain Emilia sonchifolia (other names: Tassel flower 一點 紅, 雞腳草; Fig 2), Elephantopus scaber (地膽草), Centella asiatica (積雪草), and Hedyotis diffusa (白花蛇舌草). The toxic pyrrolizidine alkaloid (PA) senkirkine was detected in the $E$ sonchifolia sample by liquid chromatography-tandem mass spectrometry as well as liquid chromatography time-of-flight mass spectrometry.

Therapeutic chest tapping was performed twice after admission for relief of respiratory distress, with subsequent insertion of chest drain due to re-accumulation of fluid. Oral diuretics (furosemide and spironolactone) were started. Due to a deranged clotting profile, anticoagulants and thrombolytic therapy were not considered. There was a good response to oral diuretics; the pleural effusion and abdominal distension gradually resolved, and the chest drain was removed on day 8 of the boy's admission.

An IVC and hepatic venogram was performed under general anaesthesia on day 


\section{毒性雙稠吡咯啶類生物鹼引起的布加綜合症}

本文報告本港一宗與毒性雙稠吡咯啶類生物噳有關的布加綜合症的病 例。一名十個月大幼兒在飲用草本飲料三個月後出現腹腔與左胸腔積 水和肝臟發大。他的臨床病徵和掃描影像都符合布加綜合症。布加綜 合症在兒科病人屬罕見病症。我們為病人安排了一連串的檢查尋找布 加綜合症的根本病因。除了在他的草本飲料中檢驗出毒性雙稠吡咯啶 類生物咸外, 其他檢查結果皆正常。

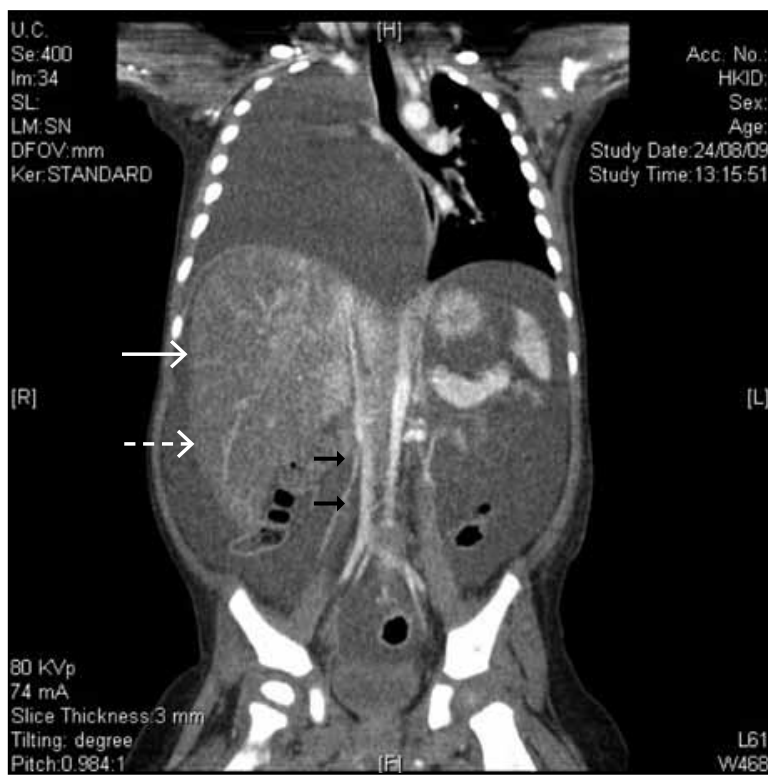

FIG I. Computed tomography shows right pleural effusion (white arrow), ascites and hepatomegaly (dotted white arrow). The intrahepatic portion of the inferior vena cava is small in calibre (black arrows)

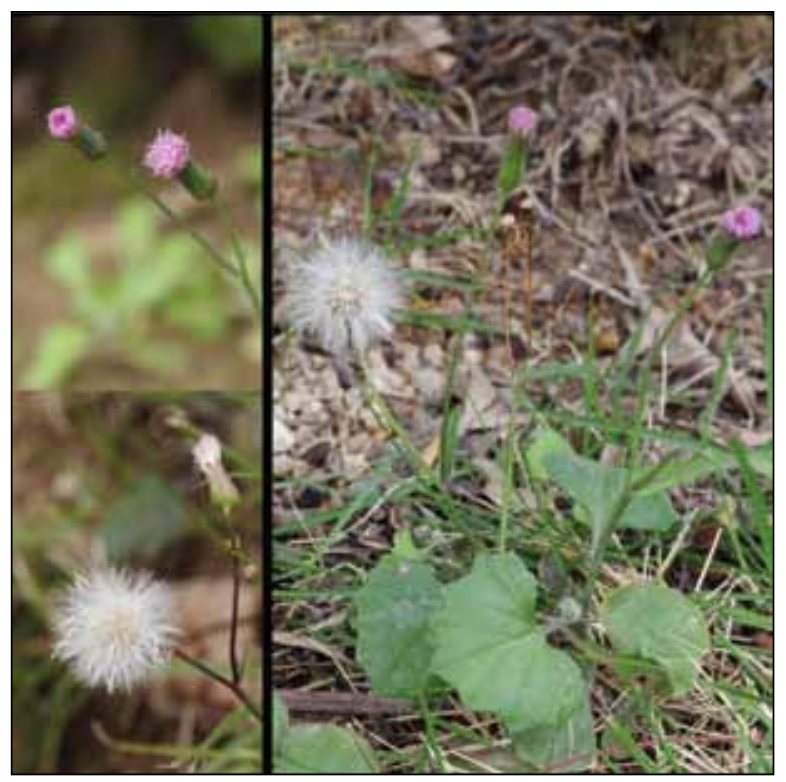

FIG 2. Emilia sonchifolia (一點紅)

Photo credit to MrYH Lam, Hong Kong

15 of hospitalisation, and showed a patent IVC with unobstructed flow and no pressure gradient. The right, left, and middle hepatic veins were also patent. No vascular web was seen. The patient improved gradually with resolution of abdominal distension; the hepatomegaly was reduced to 2 to $3 \mathrm{~cm}$ below right costal margin, and there was no re-accumulation of the pleural effusion. Oral diuretics were slowly weaned off. The ALT level decreased to $35 \mathrm{IU} / \mathrm{L}$, the clotting profile as well as protein $\mathrm{C}$ and total protein $\mathrm{S}$ levels became normal ( 0.75 and $0.94 \mathrm{IU} / \mathrm{mL}$, respectively). Repeat ultrasound of the abdomen 1 month later showed resolution of hepatic venous occlusion with restoration of the normal triphasic pattern.

Based on resolution of the hepatic venous occlusion after cessation of the herbal drinks and exclusion of other causes, this patient's hepatic disturbance was deemed secondary to toxic PA exposure. The boy's mother was advised not to give him herbal drinks again, and the patient remained well on subsequent out-patient clinic follow-up.

\section{Discussion}

Budd-Chiari syndrome is a disease complex caused by obstruction of the hepatic venous outflow at any level from the small hepatic veins to the junction of the IVC with the right atrium. ${ }^{1}$ It is usually distinguished from veno-occlusive disease (VOD), also known as sinusoidal obstruction syndrome, which is characterised by toxin-induced non-thrombotic obstruction of the microscopic centrilobular veins and small sublobular veins within the liver. Budd-Chiari syndrome is a rare disorder; one study in Sweden reports an incidence of about 1 case per million population per year. ${ }^{2}$ The incidence in children is not well reported in the literature. In $75 \%$ of patients, an underlying disorder characterised by a hypercoagulable state can be identified. ${ }^{3}$ Obstruction of a single main hepatic vein is clinically silent, occlusion of all three hepatic veins or two veins including the right hepatic vein leads to diffuse hepatic congestion and enlargement, ${ }^{4}$ resulting in ischaemic necrosis and then fibrosis. Clinical presentation depends on location, extent, and chronicity of obstruction, but common features include ascites, hepatomegaly, and abdominal pain. Doppler ultrasonography is the most useful non-invasive diagnostic test, with a sensitivity and specificity of nearly $85 \%$ for $\mathrm{BCS} .{ }^{5}$ Specific findings include abnormal flow in the major hepatic veins or IVC; thickening and irregularity of the walls of the hepatic veins as well as stenosis or dilation; and there may be inability to visualise the junction of major hepatic veins with the IVC. Compression or narrowing of the IVC is a non-specific finding. The extent of hepatic parenchymal disease, ascites, and splenomegaly can be assessed by CT. Specific findings include delayed or absent filling of the three major hepatic veins, a patchy flea-bitten appearance of the liver due to increased central relative to peripheral contrast enhancement, and narrowing of the IVC. However, the role of CT is limited due to false-positive and indeterminate results in almost half of the patients. ${ }^{6}$ Venography is the gold standard 
for diagnosis, which also provides useful information such as the extent of the thrombosis and caval pressures which help to determine optimal therapy.

After BCS was diagnosed, our patient underwent extensive workup to look for the underlying cause. The investigation results were unrevealing, whereas toxic PA in the herbal drinks prepared by his mother appeared responsible. To date, there is no method yet available to measure metabolites of PAs in body fluids. However, a possible causal association of PA and this patient's BCS is suggested by the temporal relationship of the ingestion to his presentation, and the exclusion of other known causes.

Emilia sonchifolia is a commonly found flowering plant in Hong Kong, other parts of Southern China, India, and Africa. ${ }^{7}$ It has been used in folk medicine as an antipyretic and a remedy against influenza, however it is also known to contain the toxic PA senkirkine. ${ }^{8}$ Pyrrolizidine alkaloids are a group of naturally occurring alkaloids based on the structure of the pyrrolizidine nucleus, which is reported to be present in about $3 \%$ of the world's flowering plants. ${ }^{9}$ Apparently, in their original form they have minimal toxicity, but become toxic pyrroles after metabolism in the liver. Human and livestock poisoning from PAcontaining plants has been reported in many areas of the world. Moreover, PAs have primarily caused hepatic VOD in humans, and even epidemics in developing countries such as Jamaica, India, Egypt, Iraq, and South Africa. ${ }^{10}$ A series of patients with such VOD have also been reported in the United States, Great Britain, Switzerland, northern China, and Hong Kong. ${ }^{11}$ Cases of PA-related BCS have been reported in South Africa ${ }^{12}$ and Israel, ${ }^{13}$ but are less commonly reported than VOD. We hereby report a case of PA-

\section{related BCS in Hong Kong.}

Pathogenesis of hepatotoxicity of PAs has been studied in animal models and patients with VODs. The effects of pure standard PAs on hepatocytes in vitro have been demonstrated. They include megalocytosis, increased numbers of abnormal mitoses, cytoplasmic vacuolisation, and inhibition of nucleic acid and protein synthesis. ${ }^{14}$ The pathogenesis of PA-induced BCS is less well studied. Recent studies suggest that disturbed coagulation pathways may also play an important role in its pathogenesis. ${ }^{10}$ The proposed mechanism is that PAs can cause endothelial injury and trigger the coagulation cascade. In animal models, von Willebrand factor, thrombomodulin, and several cytokines-including tumour necrosis factor-alpha (TNF- $\alpha$ ), interleukin-I beta (IL-I $\beta$ ), and endothelin-I-are released by monocytes and endothelial cells in response to PAs. Both TNF- $\alpha$ and IL-I $\beta$ are procoagulant, and stimulate the expression of several coagulation factors such as tissue factor and plasminogen activation inhibitor-I. ${ }^{15,16}$ These result in a hypercoagulable state, followed by thrombin formation in the hepatic veins and a localised consumption of the natural anticoagulants, protein $\mathrm{C}$ and protein $\mathrm{S} .^{16}$ This may explain the formation of thrombi resulting in BCS and the transient decreases in protein $C$ and total protein $\mathrm{S}$ levels in our patient.

The natural history of PA-related BCS is not well known due to the limited case reports available, but young children are believed to be the most susceptible, although the reason for this remains unclear. ${ }^{17}$ Herbal toxicity is a rare but important cause of BCS. A comprehensive drug history is important in the management of children with BCS.

\section{References}

1. Okuda K, Kage M, Shrestha SM. Proposal of a new nomenclature for Budd-Chiari syndrome: hepatic vein thrombosis of the inferior vena cava at its hepatic portion. Hepatology 1998;28:1191-8. cross ref

2. Rajani R, Melin T, Björnsson E, et al. Budd-Chiari syndrome in Sweden: epidemiology, clinical characteristics and survivalan 18-year experience. Liver Int 2009;29:253-9. cross ref

3. Valla DC. Hepatic vein thrombosis (Budd-Chiari syndrome). Semin Liver Dis 2002;22:5-14. cross ref

4. Parker RG. Occlusion of the hepatic veins in man. Medicine (Baltimore) 1959;38:369-402.

5. Bolondi L, Gaiani S, Li Bassi S, et al. Diagnosis of Budd-Chiari syndrome by pulsed Doppler ultrasound. Gastroenterology 1991;100:1324-31.

6. Gupta S, Barter S, Phillips GW, Gibson RN, Hodgson HJ. Compar-ison of ultrasonography, computed tomography and $99 m$ Tc liver scan in diagnosis of Budd-Chiari syndrome. Gut 1987;28:242-7. cross ref

7. Arthur HR, Cheung HT. A phytochemical survey of the Hong Kong medicinal plants. J Pharm Pharmacol 1960;12:567-70. cross ref

8. South African National Biodiversity Institute, the Conservatoire et Jardin botaniques de la Ville de Genève, Tela Botanica. Emilia sonchifolia. African Plant Database. Record $\mathrm{n}^{\circ}$ 95932. African Plants Database; 2008.

9. Stegelmeier BL, Edgar JA, Colegate SM, et al. Pyrrolizidine alkaloid plants, metabolism and toxicity. J Nat Toxins 1999;8:95-116.

10. Chen Z, Huo JR. Hepatic veno-occlusive disease associated with toxicity of pyrrolizidine alkaloids in herbal preparations. Neth J Med 2010;68:252-60.

11. McDermott WV, Ridker PM. The Budd-Chiari syndrome and hepatic veno-occlusive disease. Arch Surg 1990;125:5257. cross ref

12. Selzer G, Parker RG. Senecio poisoning exhibiting as Chiari's syndrome; a report on twelve cases. Am J Pathol 1951;27:885907.

13. Ghanem J, Hershko C. Veno-occlusive disease and primary hepatic vein thrombosis in Israeli Arabs. Isr J Med Sci 1981;17:339-47.

14. Zuckerman M, Steenkamp V, Stewart MJ. Hepatic venoocclusive disease as a result of a traditional remedy: confirmation of toxic pyrrolizidine alkaloids as the cause, using an in vitro technique. J Clin Pathol 2002;55:676-9. cross ref

15. Lee JH, Lee KH, Kim S, et al. Relevance of proteins $C$ and $S$, antithrombin III, von Willebrand factor, and factor VIII for the development of hepatic veno-occlusive disease in patients undergoing allogeneic bone marrow transplantation: a prospective study. Bone Marrow Transplant 1998;22:883-8. cross ref

16. Peres E, Kintzel $P$, Dansey $R$, et al. Early intervention with antithrombin III therapy to prevent progression of hepatic venoocclusive disease. Blood Coagul Fibrinolysis 2008; 19:203-7. cross ref

17. Sperl W, Stuppner H, Gassner I, Judmaier W, Dietze O, Vogel W. Reversible hepatic veno-occlusive disease in an infant after consumption of pyrrolizidine-containing herbal tea. Eur J Pediatr 1995; 154:112-6. cross ref 